\title{
Evaluation of a Personalized Subcutaneous Immunoglobulin Treatment Program for Neurological Patients
}

\author{
Adam Suleman, Lynda Theoret, Pierre Bourque, Elizabeth Pringle, \\ D. William Cameron, Juthaporn Cowan
}

\begin{abstract}
Background: Subcutaneous immunoglobulin (SCIg) treatment has been shown to control symptoms and improve overall satisfaction in patients with neurological disorders. However, a large injection volume can be overwhelming and a barrier to successful SCIg treatment. We established a nurse-led individualized approach program to facilitate a smooth and successful treatment transition from intravenous immunoglobulin (IVIg) to SCIg. The program involved a lead nurse to provide two or more individual educational sessions on SCIg administration, establish a written transition plan, and liaise care with physicians. Objectives: We aimed to evaluate the impact of our program to a successful transition defined as SCIg retention or adherence without a need to restart IVIg by six or twelve months. Methods: We reviewed medical charts of all patients with immune-mediated neuromuscular disorders who were in our program during January 2010 to Dec 2016. Results: Nineteen patients were identified. Mean IVIg treatment duration was 31.5 months (range 4-98) before the transition. Mean steady state SCIg dosage was 26.2 g/week (SD 10.3). All patients were initially able to switch to SCIg, with a retention rate of $17 / 19(89.5 \%)$ at six months and $15 / 19(78.9 \%)$ at twelve months. Two patients reverted back to IVIg treatment due to worsening of their symptoms at two and three months, while two required supplemental IVIg infusions. There were no major adverse events reported during the twelve-month period, but one minor cutaneous adverse event (redness around the injection site). Conclusions: Successful treatment transition may be achieved with the nurse led individualized approach program.
\end{abstract}

RÉSUMÉ: Évaluation d'un programme de traitement personnalisé à l'immunoglobuline par voie sous-cutanée destiné à des patients atteints de troubles neurologiques. Contexte: Il a été prouvé que les traitements à l'immunoglobuline par voie sous-cutanée (IgSC) permettent de contrôler les symptômes qui affectent des patients atteints de troubles neurologiques et d'améliorer leur satisfaction générale. Toutefois, de grands volumes injectés peuvent devenir accablants et représenter un obstacle à un traitement par IgSC qui soit efficace. Nous avons ainsi mis sur pied un programme reposant sur une approche individuelle et dirigé par du personnel infirmier afin de favoriser une transition en douceur efficace entre les traitements d'immunoglobuline par voie intraveineuse (IgIV) et ceux par IgSC. Un tel programme impliquait la présence d'une infirmière en chef chargée d'offrir deux séances de formation ou plus en ce qui concerne l'administration d'un traitement par IgSC mais aussi d'établir un plan écrit de transition entre les deux traitements et d'assurer une liaison avec les médecins traitants. Objectifs: Nous avons cherché à évaluer l'impact de notre programme en matière de transition. C'est ainsi que nous avons voulu savoir dans quelle mesure un traitement par IgSC entraînait une forme d'adhésion thérapeutique en vertu de laquelle un traitement par IgIV n'était plus nécessaire au bout de six ou de 12 mois. Méthodes: Nous avons passé en revue les dossiers médicaux de tous les patients atteints de troubles neuromusculaires d'origine auto-immune ayant fait partie de notre programme de janvier 2010 à décembre 2016. Résultats: Au total, dix-neuf patients ont été sélectionnés. Avant d'amorcer notre transition, la durée moyenne d'un traitement par IgIV était de 31,5 mois (étendue : 4-98). La posologie moyenne à l'équilibre d'un traitement par IgSC était de 26,2 g/semaine (écart-type : 10,3). Au début, tous les patients ont été en mesure de passer à un traitement par IgSC, le taux d'adhésion étant de 89,5\% (17/ 19) au bout de six mois et de 78,9 \% (15/19) au bout de douze mois. Deux patients ont recommencé à suivre un traitement par IgIV en raison d'une détérioration de leurs symptômes au bout de deux et de trois mois tandis que deux autres ont eu besoin d'injections à l'immunoglobuline additionnelles. Outre un seul événement indésirable mineur de nature cutanée, à savoir de la rougeur autour de la zone d'injection, aucun événement indésirable majeur n'a été signalé au cours de la période de transition de douze mois. Conclusions: Il est

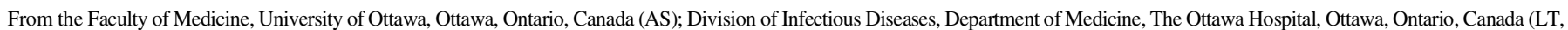

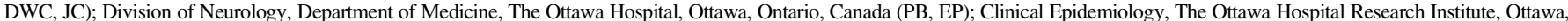
Ontario, Canada (DWC, JC).

Received July 13, 2018. Final Revisions Submitted August 26, 2018. Date of Acceptance September 16, 2018

Correspondence to: J. Cowan, PhD, The Ottawa Hospital, General Campus, 501 Smyth Road, Box 223, Ottawa, Ontario, K1H 8L6. Email: jcowan@toh.ca 
possible, au moyen d'un programme dirigé par une infirmière chef dont l'approche est individuelle, d'effectuer une transition efficace entre les deux traitements évoqués ci-dessus.

Keywords: SCIg, IVIg, Neurological disease, Immune-mediated neuropathy

doi:10.1017/cjn.2018.363

Can J Neurol Sci. 2019; 46: 38-43

\section{INTRODUCTION}

Intravenous immunoglobulin (IVIg) treatment is used as maintenance therapy for many patients with chronic neurological conditions. ${ }^{1}$ Subcutaneous immunoglobulin (SCIg) has gained popularity as it is a less invasive procedure and can be selfadministered at home for both patients with primary and secondary immunodeficiency and immune-mediated neurological disorders. $^{2,3}$ A recent systematic review and meta-analysis confirmed that SCIg treatment was as effective as IVIg treatment in patients with primary immunodeficiency, and had fewer associated side-effects. ${ }^{4}$ Our group previously reported that SCIg was an effective adjunctive therapy for the chronic management of myasthenia gravis (MG), identified by high patient satisfaction on several assessment scales. ${ }^{5}$ Many studies also suggested SCIg as a viable alternative to IVIg in the management of chronic inflammatory demyelinating polyneuropathy (CIDP) and multifocal motor neuropathy (MMN) ${ }^{3,6-8}$ SCIg is also recently approved to be used as maintenance therapy to prevent relapse of neuromuscular disability and impairment in patients with CIDP following the PATH study. ${ }^{8}$

Research has shown that patients can be effectively switched from IVIg to SCIg without deterioration in their symptoms. ${ }^{9}$ SCIg can improve quality of life and daily functioning 5 . A recently published observational study showed the successful transition of eight patients with CIDP and MMN to SCIg, with high preference for SCIg compared to IVIg and a high level of satisfaction with SCIg. ${ }^{10}$ Nevertheless, Ig dosage as a maintenance therapy for neurological patients is higher than that for patients with primary immunodeficiency $(1-2 \mathrm{~g} / \mathrm{kg} / \mathrm{month}$ vs. $0.4-0.8 \mathrm{~g} / \mathrm{kg} / \mathrm{month}){ }^{11}$ Patients may be intimidated and overwhelmed by the need for large SCIg injection volume $(100-200 \mathrm{~mL}$ of SCIg to be selfadministered weekly in a $80 \mathrm{~kg}$ patient) and/or frequent injections. A support program to assist in the transition may be essential as reported previously by Rasutis et al. who described the success of individualized training and support for patients with MMN transitioning to $\mathrm{SCIg}^{12}$ although there has not been any study comparing different treatment transition models.

We utilized the SCIg Home Infusion Program which was established for patients with primary and secondary immunodeficiency at the Ottawa Hospital (TOH) to assist neurological patients during the treatment transition phase since 2010 . We aimed to evaluate the impact of a nurse-led, patient-centered, and individualized approach on treatment transition.

\section{MeTHODS \\ Setting}

$\mathrm{TOH}$ is a large multi-centre tertiary care facility with a population catchment of 980,000 in Ottawa, Ontario. The TOH Immunodeficiency Clinic, which is embedded in the Division of
Infectious Diseases, is the only clinic in Ottawa that offers the SCIg Home Infusion Program for adult neurological patients. Patients were included in the study if they were referred by neurologists to the SCIg Home Infusion Program at TOH to transition from IVIg to SCIg between January 1, 2010 to December 31, 2016. All patients were previously diagnosed with MG, MMN, CIDP or Lambert Eaton Myasthenic Syndrome (LEMS) and prescribed IVIg by their neurologists. Each patient's neurological symptoms were stabilized by IVIg and/or other treatments prior to the referral for SCIg transition treatment.

This study was approved by the Ottawa Hospital Research Ethics Board (OHREB 20170353-01H).

\section{TOH SCIg Home Infusion Program}

The program is comprised of an Registered Nurse (RN) and two physicians. This is already an established program for primary and secondary immunodeficient patients who require immunoglobulin treatment. The programs aims to facilitate the initiation of SCIg treatment or transition of SCIg from IVIg treatment. The RN plays a major role as a case manager of each patient. The typical treatment dosage in neurological patients is significantly higher than patients with primary or secondary immunodeficiency. Therefore, an individualized approach was designed to minimize stress but ensure the success of the transition for neurological patients.

\section{Introduction to SCIg Treatment:}

At the patient first visit, the physician reviewed the patient's diagnosis, previous history of treatment, adverse effects from IVIg treatment, and informed the patient briefly about how SCIg work. The RN met the patient at the same visit and provided education about the SCIg treatment including showing what materials were involved, how the SCIg product looked, and what was expected during or after the infusion. A pamphlet of the SCIg product information was also provided. Patient and caregiver information was gathered to inform a care plan for the patient including who would administer the SCIg infusion for the patient. The RN arranged a first SCIg treatment visit, which was typically within four weeks.

\section{SCIg Dosage Calculation:}

All patients received a $20 \%(0.2 \mathrm{~g} / \mathrm{ml}) \mathrm{SCIg}$ product (Hizentra $^{\circledR}$, CSL Behring). The SCIg dosage was calculated based on the pharmacokinetics data of the $20 \%$ IgPro20 formulation data documented in primary immunodeficiency. ${ }^{13}$ A conversion factor of 1.20 (20\% increase) was applied to the patient's steady-state monthly IVIg dosage. This total was then converted to a weekly dosage amount. To calculate the volume $(\mathrm{mL})$ of infusate, the dosage in grams was multiplied by a factor of five. 


\section{SCIg Infusion Induction Period:}

Pump assisted and manual push methods were offered. A pump assisted infusion method was offered if the weekly dosage was higher than $16 \mathrm{~g}$ or $80 \mathrm{~mL}$ or if patients had impaired dexterity. All patients and caregivers attended sessions of a one-onone SCIg infusion demonstration session held by the RN on at least two occasions prior to self-injection at home. The initial infusion volume was a maximum tolerated volume, typically $10-15 \mathrm{~mL}$ per infusion site. The number of infusion sites ranged from 1 to 4 sites, depending on patient's preference. The infusion locations could be abdomen, inner thighs, or upper arms. The initial infusion flow rate was $0.5 \mathrm{~mL} /$ minute. The patient was given a written instruction to increase the infusion frequency from weekly to twice weekly at the same volume for two weeks, and subsequently to three times weekly if necessary to reach the final target dosage. Patients were allowed autonomy in adjusting the infusion flow rate to the maximally tolerable level and were instructed to titrate up when they felt ready. During this transitional phase, the patients still received IVIg.

\section{Follow-up:}

All patients were encouraged to contact the $\mathrm{RN}$ at any time. The RN also followed-up on each patient at least monthly by phone calls and/or electronic mail to improve adherence. The referring neurologists clinically assessed all patients at least every six months, and communicated with the RN if there was a need to adjust treatment dosage.

\section{Measures}

Demographic data was collected for each patient, including referral diagnosis, age and sex. Treatment data, including IVIg start date, transition date, overlap time from IVIg to SCIg, transition dosing and number of weeks on SCIg was collected. Medical charts were reviewed to assess patient symptoms at follow-up visits.

The primary outcome was the successful transition rate at two different time points: six and twelve months. A successful transition was defined by SCIg retention without the need to switch to IVIg or addition of supplemental IVIg. Secondary outcomes were subjective changes in neurological status while on SCIg in comparison to IVIg and adverse events.

\section{Analysis}

The sample was described using frequencies and proportions, and continuous measures were displayed using mean and ranges. All analyses were conducted using SPSS Version $20^{14}$.

\section{RESULTS}

A total of 21 patients had been referred to the outpatient SCIg Home Infusion Program between January 1, 2010 to December 31, 2016. Two patients were excluded from the analysis. One patient had no neurological follow-up within the study timeframe, and the other patient had a single dose of IVIg and had to stop because of a severe reaction. The latter patient's neurological symptoms were therefore not yet stabilized before the start of SCIg.

Of 19 included patients, $9(47.4 \%)$ were diagnosed with $\mathrm{MG}$, 5 (26.3\%) with MMN, 4 (21.0\%) with CIDP, and 1 (5.3\%) with LEMS. Patient baseline characteristics are described in Table 1. The mean age of patients in the study was 54 years (range of 35 to
73 years), and nine (47.4\%) patients were female. Most patients with MG were taking concurrent immunosuppressive medications, primarily prednisone $(3 / 9,33 \%)$ or azathioprine $(4 / 9,44 \%)$. Half of the patients with CIDP were taking prednisone (2/4), and patients with $\mathrm{MMN}$ were on no additional therapy. The mean overlap time during the transition from IVIg to SCIg was 1.7 months, with a range of 0 to 4 months. The mean baseline IVIg dosage was $23.1 \mathrm{~g} / \mathrm{wk}$ (SD 12.1). All 19 patients were able to selfadminister SCIg treatment and reach the target dosage with a mean timeline of 3.4 weeks (SD 2.7). All patients except one used pump assisted SCIg administration. Twelve patients used $27 \mathrm{G}$ needles, while six used $24 \mathrm{G}$ needles and one used $25 \mathrm{G}$ needles. The length of the needles was $12 \mathrm{~mm}$ in most cases except for two patients who required a shorter needle length of $9 \mathrm{~mm}$ and one patient who required a longer needle length of $15 \mathrm{~mm}$. The injection site was the abdomen for all 19 patients. The average infusion volume/site was $14.9 \mathrm{~mL}$ (range of 11.25-20) and the average number of injection sites was 2.25 (range of 1-3). The infusion parameters are summarized in Table 2.

The successful transition to SCIg was $89.5 \%$ (17/19) at six months and $78.9 \%(15 / 19)$ at twelve months. There were four patients with transition failure and the characteristics and rationale are detailed in Table 3. Two patients, who both had a diagnosis of MMN, restarted on IVIg by six months, and another two patients required a booster IVIg by twelve months. Reasons for failure to transition were patient preference of IVIg over SCIg, and incomplete recovery of neurological symptoms.

The majority of patients perceived that their neurological symptoms either did not change or improved (79\% and $68.4 \%$ at six and twelve months, respectively) while on SCIg as compared to IVIg. Four patients $(21.0 \%)$ found that their neurological symptoms worsened at six months, and six patients (31.6\%) found their symptoms to worsen after twelve months. Among the six patients, two were maintained on SCIg as their symptoms did not affect their function and the patients desired to continue on SCIg treatment.

Table 1: Baseline patient characteristics $(n=19)$

\begin{tabular}{|c|c|}
\hline Variables & $n(\%)$ \\
\hline Age, years (mean, range) & $54(35-73)$ \\
\hline Female $(n, \%)$ & $9(47.4 \%)$ \\
\hline \multicolumn{2}{|l|}{ Referral Diagnosis $(n, \%)$} \\
\hline MG & $9(47.4 \%)$ \\
\hline $\mathrm{MMN}$ & $5(26.3 \%)$ \\
\hline CIDP & $4(21.0 \%)$ \\
\hline LEMS & $1(5.3 \%)$ \\
\hline Overlap Time from IVIg to SCIg, months (mean, range) & $1.7(0-4)$ \\
\hline Previous IVIg dose, g per week (mean, range) & $23.3(12.5-56.7)$ \\
\hline Time on IVIg, months (mean, range) & $31.5(4-98)$ \\
\hline Initial dose of SCIg, g per week (mean, range) & $19.5(4-33)$ \\
\hline Mean steady state dose of SCIg, g per week (mean, range) & $26.2(12-60)$ \\
\hline Time to target SCIg, weeks (mean, range) & $3.4(0-8)$ \\
\hline \multicolumn{2}{|c|}{$\begin{array}{l}\text { CIDP = chronic inflammatory demyelinating polyneuropathy, IVIg = } \\
\text { intravenous immunoglobulin, LEMS = Lambert Eaton Myasthenic Syn- } \\
\text { drome, MG = myasthenia gravis; MMN = multifocal motor neuropathy; } \\
\text { SCIg = subcutaneous immunoglobulin }\end{array}$} \\
\hline
\end{tabular}




\section{Table 2: SCIg infusion parameters}

\begin{tabular}{l|c}
\hline Variables & $\boldsymbol{n}(\boldsymbol{\%})$ \\
\hline Method & $18(94.7 \%)$ \\
\hline pump & $1(5.3 \%)$ \\
\hline push & $2(10.5 \%)$ \\
\hline Needle size & $10(52.6 \%)$ \\
\hline $27 \mathrm{~g} / 9 \mathrm{~mm}$ & $1(5.3 \%)$ \\
\hline $27 \mathrm{~g} / 12 \mathrm{~mm}$ & $6(31.6 \%)$ \\
\hline $25 \mathrm{~g} / 15 \mathrm{~mm}$ & $3.8(2-4)$ \\
\hline $24 \mathrm{~g} / 12 \mathrm{~mm}$ & $14.9(11.25-20)$ \\
\hline Number of infusion sites (mean, range) & $2.25(1-3)$ \\
\hline Initial volume (ml)/site (mean, range) & \\
\hline Frequency of infusion/week (mean, range) & \\
\hline
\end{tabular}

$\mathrm{SCIg}=$ subcutaneous immunoglobulin

It is of particular note that throughout the twelve-month followup period, there were no moderate or severe adverse events such as fever, nausea, vomiting, venous thromboembolism or anaphylaxis. Only one patient reported redness at the site of injection.

\section{DISCUSSION}

The TOH SCIg Home Infusion Program for patients with immune-mediated neurological disorders led to $89.5 \%$ and $78.9 \%$ successful transition rate from IVIg to SCIg at six and twelve months. We demonstrated that having a dedicated program nurse who provided education, treatment assessment, and support is an important component of successful SCIg transition. This is consistent with Rasutis et al. who also demonstrated the importance of a specialized RN to ensure that the patients have access to technical and psychosocial support in the SCIg transition process. ${ }^{12}$

Among the four patients who failed to stay on SCIg treatment alone, two main observations were noted. First, three patients had MMN, and second, two had minimal or no IVIg/SCIg treatment overlaps. We propose that the SCIg dosage could be too low in our MMN patients as one study suggested that patients with $3 / 15$ MMN cases developed intolerable weakness by the third month despite a dosage conversion ratio of 1:1.53 from IVIg to SCIg. ${ }^{15}$ In addition, among the six patients who reported worsening neurological symptoms, four had MMN, while there were only five MMN cases in our cohort. In contrast, all patients with MG and CIDP in our study did well on SCIg at 1:1.2 conversion ratios. This further suggests that a failed SCIg transition in our MMN patients could be due to low IVIg:SCIg conversion ratio. We also propose that two patients did not achieve successful SCIg transition because of minimal or no IVIg/SCIg treatment overlap as supported by a recent "proof-of-concept" study which demonstrated a smooth treatment transition using an overlap of IVIg and SCIg treatment period that lasted up to eight weeks. ${ }^{9}$

Six patients in our cohort had worsening muscle weakness on SCIg by 12 months. This was thought to be related to the underlying neuromuscular disease rather than a side effect of SCIg, though this cannot be confirmed in the absence of a control group that remains on IVIG. A recent prospective trial found that only one patient out of 87 had neuropathy progression on SCIg. ${ }^{16}$ However, that trial only observed patients with CIDP or MMN for four months. In our study, the two patients with MMN who transitioned back to IVIg did so after four months. We recommend

Table 3: Characteristics of patients who did not reach SCIg successful transition $(n=4)$

\begin{tabular}{|c|c|c|c|c|c|c|c|}
\hline Patient & Diagnosis & Reason for non-retention & $\begin{array}{l}\text { Target } \\
\text { SCIg }\end{array}$ & $\begin{array}{l}\text { Overlap } \\
\text { Time from } \\
\text { IVIg to } \\
\text { SCIg (mo) }\end{array}$ & Extent of neurological disease at diagnosis & $\begin{array}{l}\text { Other } \\
\text { Treatments } \\
\text { Received }\end{array}$ & $\begin{array}{l}\text { Length of } \\
\text { IVIg }\end{array}$ \\
\hline $1^{*}$ & MMN & $\begin{array}{l}\text { MMN symptoms were not } \\
\text { adequately controlled with } \\
\text { SCIg. Patient felt that injecting } \\
\text { SCIg was inconvenient. }\end{array}$ & $24 \mathrm{~g} / \mathrm{wk}$ & $0^{\text {******* }}$ & $\begin{array}{l}\text { Abnormalities confined to left arm: weakness in left } \\
\text { biceps, wrist extensors ( } 3 / 5 \text { strength). }\end{array}$ & None & 27 months \\
\hline $2^{*}$ & MMN & $\begin{array}{l}\text { Patient had residual weakness and } \\
\text { preferred IVIg to SCIg. }\end{array}$ & $24 \mathrm{~g} / \mathrm{wk}$ & 3 & $\begin{array}{l}\text { Multifocal motor neuropathy with conduction block. } \\
\text { Hypertrophy of the left upper trapezius muscle with } \\
\text { fasciculation, weakness in left triceps ( } 4 / 5 \text { strength), } \\
\text { wrist extensors ( } 4-/ 5 \text { strength), and finger extensors (3/ } \\
5 \text { strength). }\end{array}$ & None & 8 months \\
\hline $3^{* *}$ & MMN & $\begin{array}{l}\text { Patient had residual upper arm } \\
\text { weakness despite titrating up } \\
\text { SCIg dose. }\end{array}$ & $64 \mathrm{~g} / \mathrm{wk}$ & 3 & $\begin{array}{l}\text { On IVIg for nine years. Neurological symptoms while on } \\
\text { IVIg include weakness of right upper arm, forearm and } \\
\text { wrist. }\end{array}$ & None & 60 months \\
\hline $4^{* * * *}$ & LEMS & $\begin{array}{l}\text { Patient had residual symptoms, } \\
\text { was advised to SCIg and was } \\
\text { started on IVIg as a new regime. }\end{array}$ & $27 \mathrm{~g} / \mathrm{wk}$ & 1 & $\begin{array}{l}\text { Unable to rise from chair without using her arms. } 4 / 5 \\
\text { proximal strength in upper and lower extremities. } \\
\text { Muscle-strength reflexes are grade } 1 \text { in upper } \\
\text { extremity and absent in lower extremity. }\end{array}$ & $\begin{array}{l}\text { 3,4-DAP } \\
\text { (80mg/d) } \\
\text { Mestinon } \\
\text { (60mg b. } \\
\text { i. d.) }\end{array}$ & 11 months \\
\hline
\end{tabular}

IVIg = intravenous immunoglobulin, LEMS = Lambert Eaton Myasthenic Syndrome, MMN = multifocal motor neuropathy, SCIg $=$ subcutaneous immunoglobulin

*The patients switched back to IVIg

${ }^{* * *}$ The patient received boosted IVIg at $60 \mathrm{~g}$ every three months in addition to SCIg

${ }^{* * *}$ The patient received boosted IVIg at $65 \mathrm{~g}$ every three weeks on an as needed basis in addition to SCIg

***** The patient had last dose of IVIg two weeks prior to the initiation of SCIg but then travelled out of the country, which prevented an adequate overlap treatment 
following patients for a longer period of time in order to best determine the effect of the transition.

None of our patients had the major complications of fever, headache, extreme fatigue, or rarer but more severe consequences such as venous thromboembolism, despite high dosage. ${ }^{17}$ Only two patients experienced some weakness three to four days prior to next SCIg infusion. This is consistent with literature suggesting that patients with neurological disorders have fewer fever and nausea symptoms on SCIg compared to IVIg, with fewer fluctuations related to injection times. ${ }^{6,18,19}$ Only one patient reported a side effect of redness around the injection site. Given the retrospective nature of this study, there may be some cases of erythema that were missed, however the absence of these cases from clinical notes suggests that, if present, they were likely insignificant to patients.

Of note, the patient who was excluded from this study due to non-stabilized neurological symptoms prior to $\mathrm{SCIg}$ treatment transition had developed severe headache and phlebitis while on IVIg, did very well on SCIg without any adverse reaction. This demonstrates the possibility of using SCIg as a method of treatment for neurological patients who have adverse events related to their IVIg infusions.

SCIg treatment has been shown to be cost effective as compared to IVIg treatment in Canada and Switzerland. ${ }^{20,21}$ The net economic gain from switching one patient to home-based SCIg care would be estimated to be Can $\$ 2,603$ in year 1 and Can $\$ 2,948$ each year thereafter based on available data. ${ }^{20,21}$ Switching $37 \mathrm{IVIg}$ primary and secondary immunodeficient patients to SCIg would gain one nurse full-time equivalent. Although we did not perform health economics analysis, we demonstrated that 15 of the 19 patients no longer required monthly or bi-monthly visits to the hospital medical day unit. This translates into 900 - 1800 hours/ year of the medical day unit space and nursing time. The magnitude of cost saving can be offset by higher dose of SCIg required. However, recent data has shown that lower doses of SCIg are welltolerated in patients with CIDP, which would support SCIg as a cost-effective therapy ${ }^{8}$. Other models of treatment transition exist such as the subcutaneous immunoglobulin home infusion program in British Columbia which may prove to be cost-effective. ${ }^{22}$

There were several limitations to this retrospective cohort study. First, the patient cohort is small, although similar in sample size to studies investigating rare condition. Second, as there was not a control group who transitioned to SCIg without a nursing support program, we are unable to quantify the effect of the nursing program, but rather these results describe the success of the nursing program as assessed by the high success rates. Third, the reported neurological symptoms described were assessed through a chart review and not formally assessed using a validated symptom assessment scale by the neurologist. As a result it is difficult to objectively define improvement or worsening of symptoms. It is also likely that common minor symptoms, such as erythema around the injection site, were not documented in patient charts which may explain the low rate of minor adverse events described. Finally, adverse events were likely underreported due to the nature of the retrospective data collection.

\section{Conclusion}

This study reports the successful transition of 15 out of 19 patients from IVIg to SCIg for the maintenance of their neurological conditions under a nurse-led approach to guide the transition. A critical component of our program is the nurse-led and individualized approach designed to facilitate the transition process by providing teaching sessions and answering questions at any point while the patient is on SCIg. Our patient cohort did not report any significant adverse events. SCIg has been shown in multiple studies to improve the quality of life of patients by reducing the need for hospital visits, and reducing the severity of side-effects seen with IVIg treatment. ${ }^{4,5}$ Our study suggests that SCIg is a viable alternative to IVIg for maintenance of neurology symptoms, and is successful with a designated RN to facilitate the individualized treatment.

\section{ACKNOWLEDGMENT}

The authors would like to thank Katherine Muldoon for her assistance in the editing of this article.

\section{FinanCial Support}

This work was supported by CSL Behring; however, CSL Behring was not involved in the study conduct including study conception, data collection, data analysis, data interpretation and manuscript preparation.

\section{Disclosures}

Adam Suleman, Pierre Bourque, and Elizabeth Pringle have nothing to disclose.

D. William Cameron reports grants and other from CSL Behring, grants and other from Grifols, other from Baxalta, other from Pfizer, other from Merck, other from Octapharma, and other from Shire, outside the submitted work.

Juthaporn Cowan reports grants from CSL Behring, during the conduct of the study, and other from Octapharma and other from Shire, outside the submitted work.

Lynda Theoret (RN) reports other from CSL Behring, other from OctaPharma, and other from Shire, outside the submitted work.

\section{REFERENCES}

1. Lünemann JD, Quast I, Dalakas MC. Efficacy of intravenous immunoglobulin in neurological diseases. Neurother $\mathbf{J}$ Am Soc Exp Neurother. 2016;13(1):34-46.

2. Windegger TM, Lambooy CA, Hollis L, Morwood K, Weston H, Fung YL. Subcutaneous immunoglobulin therapy for hypogammaglobulinemia secondary to malignancy or related drug therapy. Transfus Med Rev. 2017;31(1):45-50.

3. Leussink VI, Hartung H-P, Kieseier BC, Stettner M. Subcutaneous immunoglobulins in the treatment of chronic immune-mediated neuropathies. Ther Adv Neurol Disord. 2016;9(4):336-43.

4. Shabaninejad H, Asgharzadeh A, Rezaei N, Rezapoor A. A comparative study of intravenous immunoglobulin and subcutaneous immunoglobulin in adult patients with primary immunodeficiency diseases: a systematic review and meta-analysis. Expert Rev Clin Immunol. 2016;12(5):595-602.

5. Bourque PR, Pringle CE, Cameron W, Cowan J, Chardon JW. Subcutaneous immunoglobulin therapy in the chronic management of myasthenia gravis: a retrospective cohort study. PLoS ONE. 2016;11 (8):e0159993. https://doi.org/10.1371/journal.pone.0159993.

6. Markvardsen LH, Harbo T. Subcutaneous immunoglobulin treatment in CIDP and MMN. Efficacy, treatment satisfaction and costs. J Neurol Sci. 2017;378:19-25.

7. Harbo T, Andersen H, Jakobsen J. Long-term therapy with high doses of subcutaneous immunoglobulin in multifocal motor neuropathy. Neurology. 2010;75(15):1377-80.

8. van Schaik IN, Bril V, van Geloven N, et al. Subcutaneous immunoglobulin for maintenance treatment in chronic inflammatory 
demyelinating polyneuropathy (PATH): a randomised, double-blind, placebo-controlled, phase 3 trial. Lancet Neurol. 2018;17(1):35-46.

9. Misbah SA, Baumann A, Fazio R, et al. A smooth transition protocol for patients with multifocal motor neuropathy going from intravenous to subcutaneous immunoglobulin therapy: an open-label proofof-concept study. J Peripher Nerv Syst JPNS. 2011;16(2):92-7.

10. Hadden RDM, Marreno F. Switch from intravenous to subcutaneous immunoglobulin in CIDP and MMN: improved tolerability and patient satisfaction. Ther Adv Neurol Disord. 2015;8(1):14-9.

11. Fadeyi M, Tran T. Calculating the dose of subcutaneous immunoglobulin for primary immunodeficiency disease in patients switched from intravenous to subcutaneous immunoglobulin without the use of a dose-adjustment coefficient. Pharm Ther. 2013;38(12):768-70.

12. Rasutis VM, Katzberg HD, Bril V. High-dose subcutaneous immunoglobulin in patients with multifocal motor neuropathy: a nursing perspective. J Infus Nurs Off Publ Infus Nurses Soc. 2017;40 (5):305-12.

13. Wasserman RL, Melamed I, Nelson RP, et al. Pharmacokinetics of subcutaneous IgPro20 in patients with primary immunodeficiency. Clin Pharmacokinet. 2011;50(6):405-14.

14. IBM SPSS Statistics 20 Available for Download - United States [Internet]. 2016 [cited 2018 May 9]. Available from: http://www. ibm.com/support, https://www-304.ibm.com/support/docview. wss?uid=swg21509012

15. Katzberg HD, Rasutis V, Bril V. Subcutaneous immunoglobulin for treatment of multifocal motor neuropathy. Muscle Nerve. 2016;54 (5):856-63.
16. Cocito D, Merola A, Peci E, et al. Subcutaneous immunoglobulin in CIDP and MMN: a short-term nationwide study. J Neurol. 2014;261(11):2159-64.

17. Orbach H, Katz U, Sherer Y, Shoenfeld Y. Intravenous immunoglobulin: adverse effects and safe administration. Clin Rev Allergy Immunol. 2005;29(3):173-84.

18. Markvardsen LH, Christiansen I, Andersen H, Jakobsen J. Headache and nausea after treatment with high-dose subcutaneous versus intravenous immunoglobulin. Basic Clin Pharmacol Toxicol. 2015;117(6):409-12.

19. Racosta JM, Sposato LA, Kimpinski K. Subcutaneous versus intravenous immunoglobulin for chronic autoimmune neuropathies: A meta-analysis. Muscle Nerve. 2017;55(6):802-9.

20. Gerth WC, Betschel SD, Zbrozek AS. Implications to payers of switch from hospital-based intravenous immunoglobulin to home-based subcutaneous immunoglobulin therapy in patients with primary and secondary immunodeficiencies in Canada. Allergy Asthma Clin Immunol Off J Can Soc Allergy Clin Immunol. 2014;10(1):23.

21. Perraudin C, Bourdin A, Spertini F, Berger J, Bugnon O. Switching patients to home-based subcutaneous immunoglobulin: an economic evaluation of an interprofessional drug therapy management program. J Clin Immunol. 2016;36(5):502-10.

22. Subcutaneous Immunoglobulin Home Infusion Program I Providence Health Care [Internet]. [cited 2018 Aug 11]. Available from: http:// www.providencehealthcare.org/subcutaneous-immunoglobulinhome-infusion-program 